\title{
Exposure to exogenous estrogens in food: possible impact on human development and health
}

\author{
Anna-Maria Andersson and Niels E Skakkebæk \\ University Department of Growth and Reproduction, Rigshospitalet, Copenhagen, Denmark \\ (Correspondence should be addressed to N E Skakkebaek, Department of Growth and Reproduction, GR 5064, Rigshospitalet, Blegdamsvej 9, \\ DK-2100 Copenhagen Ø, Denmark; Email: nes@rh.dk)
}

\begin{abstract}
There has been increasing concern about the impact of environmental compounds with hormone-like action on human development and reproductive health over the past decades. An alternative but neglected source of hormone action that may be considered in this connection is hormone residues in meat from husbandry animals treated with sex steroid hormones for growth promotion. Treatment of cattle with naturally occurring or synthetic sex hormones may enhance lean muscle growth and improve feed efficiency and is therefore a very cost effective procedure for cattle producers who have used it for decades in some Western countries, including the USA and Canada. The Joint Food and Agricultural Organisation/World Health Organisation (FAO/WHO) expert committee on food additives (JECFA) and the US Food and Drug Administration (FDA) considered, in 1988, that the residues found in meat from treated animals were safe for the consumers.

We have re-evaluated the JECFA conclusions regarding the safety of estradiol residues in meat in the light of recent scientific data, with special emphasis on estradiol levels in prepubertal children. These levels are needed for estimates of the normal daily production rates of estradiol in children, who may be particularly sensitive to low levels of estradiol.

In our opinion, the conclusions by JECFA concerning the safety of hormone residues in meat seem to be based on uncertain assumptions and inadequate scientific data. Our concerns can be summarized as follows. 1) The data on residue levels in meat were based on studies performed in the $1970 \mathrm{~s}$ and $1980 \mathrm{~s}$ using radioimmunoassay (RIA) methods available at the time. The sensitivity of the methods was generally inadequate to measure precisely the low levels found in animal tissues, and considerable variation between different RIA methods for measuring steroids exists. Therefore the reported residue levels may be subject to considerable uncertainty. 2) Only limited information on the levels of the various metabolites of the steroids was given despite the fact that metabolites also may have biological activity. 3) Reliable data on daily production rates of steroid hormones were and are still lacking in healthy prepubertal children. This lack is crucial as previous guidelines regarding acceptable levels of steroid residues in edible animal tissues have been based on very questionable estimates of production rates in children. Thus, even today the US FDA bases its guidelines on the presumably highly overestimated production rates in prepubertal children given in the JECFA 1988 report. 4) The possible biological significance of very low levels of estradiol is neglected.

In conclusion, based on our current knowledge possible adverse effects on human health by consumption of meat from hormone-treated animals cannot be excluded.
\end{abstract}

European Journal of Endocrinology $140477-485$

\section{Introduction}

Over the past decades there have been several reports concerning adverse trends in male reproductive health and the possible role of environmental chemicals with hormone-like action. The presence of these so-called xenohormones in our environment has caused increasing concern about their impact on wildlife and human health (1-3). Focus has especially been on compounds with estrogen-like action - the xenoestrogens. Exposure to these compounds may occur not only through industry and agriculture. As some of these compounds are used in food production and food packaging one route of exposure that has caused concern is diet (e.g. pesticide residues on fruit and vegetables, food contaminated by compounds found in can lining and plastic wrapping etc.). The effects of dietary exposure to naturally occurring xenoestrogens like the phytoestro- 
gens, which are found in rich amount in certain plants, and mycoestrogen from fungi have also been considered (3). In contrast, the possible exposure to endogenous sex steroids from food has not been widely discussed. As estradiol is 10000 -fold more biopotent than most identified environmental xenoestrogens, it is highly relevant to consider also the dietary exposure to natural sex steroids including estradiol, and their possible impact on human development and health.

The naturally occurring sex steroids estradiol, progesterone, and testosterone have growth promoting effects in man and animals. Due to the improvement of weight gain and feed efficiency in meat-producing animals, administration of exogenous sex steroids has been used in agricultural practice in the USA for almost 50 years. In addition, three potent synthetic chemicals with estrogenic (zeranol), gestagenic (melengestrol acetate) and androgenic (trenbolone acetate) action are also widely used for growth promotion in cattle. With the exception of melengestrol acetate, the recommended administration of hormones is by subcutaneous implantation of continuously releasing hormone pellets in the ear. There is no withdrawal time for any of the approved implants - the ear, along with any residual drug, is discarded at slaughter. Melengestrol acetate is administered in cattle feed. A significant part of cattle raised in US feedlots are treated with growth promoting sex hormones. The most widely used substances are estrogens, either in the form of estradiol- $17 \beta$, estradiol benzoate or the synthetic zeranol. Progesterone, testosterone and the two synthetic hormones trenbolone acetate and melengestrol acetate are generally used in combination with estrogen. Bulls intended for reproduction are not treated with sex hormone implants as treatment may result in delayed testicular development and reduced fertility. Likewise, treatment of heifers intended for reproduction is not recommended. Sex hormone treatment is also not used in dairy animals in the USA. In Europe, the use of hormonal drugs in animal meat production has officially been prohibited since 1989.

When trying to evaluate whether sex hormone treatment in animal production may lead to adverse effects on human health several aspects have to be considered. The following questions should be answered. Are the levels of residues of sex steroids and their metabolites in edible tissues from treated animals significantly elevated compared with the naturally occurring levels of these substances in the relevant animals? Are the excess levels of residues of sex steroids and their metabolites in edible tissues from treated animals significant with regard to the physiological levels of these substances in humans? What do we know about the biological effects of these substances in humans in the doses that we can expect from intake of tissue from treated animals?

In this review, we have focused on the possible effects of estradiol as estrogens are the most potent of the sex steroids and the most widely used growth promoters in cattle. As some of our comments and points may also be relevant for the other sex steroids, these are also considered when appropriate.

\section{Residues of sex steroids and their metabolites in edible tissues from treated animals}

The data on residues in edible tissue after treatment of cattle with hormone releasing implants has been reviewed by the joint Food and Agricultural Organisation/ World Health Organisation (FAO/WHO) expert committee on food additives (JECFA) in 1988 (4). Levels found in non-treated (control) and treated cattle (including veal calves, heifers, steers, bulls and pregnant heifers) after different doses and mixtures of naturally occurring sex steroids were considered. The assays used to measure steroid residues in animal tissues were, in general, based on the radioimmunoassay (RIA) method. It should, however, be noted that the residue levels found in both untreated and treated animals were often close to or at (if not below) the detection limit of the assays used. Furthermore, as was also pointed out by JECFA, a large variation existed in the levels obtained with different assays. Thus, the reported levels of sex steroid residues (4) most likely are subject to substantial uncertainty. The general conclusion of the JECFA report was that residue levels of estradiol, estrone, progesterone, and testosterone in animal tissue were all significantly increased (around twofold or more) in treated cattle as compared with untreated calves, heifers and steers (4). However, the residue levels measured in tissues from treated cattle were all substantially lower than the levels found in untreated pregnant heifers. Thus, residue levels measured in tissues from treated animals fall well within the normal physiological range if the highest levels of testosterone found in mature bulls and the highest levels of estradiol and progesterone found in pregnant heifers were used as references. The significance of increased estrogen levels in nonpregnant treated animals will, however, depend on how small a fraction of the slaughtered cattle is constituted by pregnant heifers (especially heifers in late pregnancy, where hormone levels are most elevated). Hence, if hormone implants result in a significant increase in sex steroid residue levels in the edible tissues from the bulk of the slaughtered cattle, then the overall load of sex steroid intake from meat consumption will, nevertheless, be increased. In addition, the practice of treating cattle with sex steroid hormones may contribute to an increased load of these hormones not only through consumption of meat from treated animals, but also via an increased excretion of these compounds and their metabolites to the environment where they, theoretically, may end up in the drinking water. 


\section{Endogenous production of sex steroids in humans, especially in prepubertal children}

Estradiol, progesterone and testosterone are substances that are naturally occurring in both human and animals in identical molecular forms. However, the major metabolites of these compounds may differ in different species, as the metabolism can be species specific. The naturally occurring sex steroids that are taken up by consumption of animal tissue will, therefore, have the same biological activity in the human body as the endogenously produced hormones. Whether exogenous steroids have a significant impact on the biological processes in the body presumably depends on the exogenous doses supplied in relation to the endogenous production of steroid.

In the US Food and Drug Administration's (FDA) guidelines for compounds used in food-producing animals, the conclusion regarding the use of natural sex steroids is: '..that no physiological effect will occur in individuals chronically ingesting animal tissues that contain an increase of endogenous steroid equal to $1 \%$ or less of the amount in micrograms produced by daily synthesis in the segment of the population with the lowest daily production. In the case of estradiol and progesterone, prepubertal boys synthesize the least; in the case of testosterone, prepubertal girls synthesize the least.' (5).

From this it is clear that the limit of an acceptable increased exposure to naturally occurring sex hormones by consuming treated animal tissue suggested by FDA is based on an estimate of the endogenous daily production of these steroids in prepubertal boys and girls. Estimates of daily production rates for estradiol and progesterone in prepubertal boys and for testosterone in prepubertal girls are given in the guidelines and correspond to $6 \mu \mathrm{g} /$ day estradiol and $150 \mu \mathrm{g} /$ day progesterone in boys and $32 \mu \mathrm{g} /$ day testosterone in girls. Identical production rates were also given in the "Thirty-second report of the joint FAO/WHO expert committee on food additives: Evaluation of certain veterinary drug residues in food' (6).

Daily production rates (PR) of hormones are calculated from estimates of the metabolic clearance rate (MCR, the volume of serum that can be cleared of a given hormone during $24 \mathrm{~h}$ ) and of the plasma concentrations of the given hormone by the following equation:

$$
\begin{aligned}
\mathrm{PR}(\mu \mathrm{g} / \text { day })= & \text { plasma concentration }(\mu \mathrm{g} / \mathrm{ml}) \\
& \times \operatorname{MCR}(\mathrm{ml} / \text { day })
\end{aligned}
$$

However, to our knowledge, estimated MCRs for estradiol, testosterone or progesterone in healthy prepubertal children have never been published and most likely do not exist (due to questionable ethics in performing such studies, which would involve injection of radioactive hormones in healthy children). In the late
$1960 \mathrm{~s}$ and the $1970 \mathrm{~s}$, several papers were published giving MCRs for sex steroids and some of their metabolites in adult men and women (7-12). MCRs have been published for testosterone in prepubertal children with congenital adrenal hyperplasia (13) and in two prepubertal individuals with androgen resistance (11). However, in both these conditions the endogenous hormone milieu is highly abnormal due to the disease state and the MCRs obtained in these prepubertal patients cannot be considered to reflect MCRs in healthy prepubertal children.

Due to the lack of information on MCRs for estradiol, progesterone and testosterone in prepubertal children, it is obscure how the PRs stated in the Thirty-second report on the joint $\mathrm{FAO} / \mathrm{WHO}$ expert committee on food additives: Evaluation of certain veterinary drug residues in food have been constructed. The papers that the report refers to regarding the PR of estradiol (14) and progesterone (15) in prepubertal boys, and the PR of testosterone in prepubertal girls $(11,13)$ do not give any information on the MCRs or PRs in healthy prepubertal children. They do, however, give information on the plasma concentrations of these hormones in children. PRs for estradiol, progesterone, and testosterone in prepubertal children are, nevertheless, stated in the JECFA report and seem to be calculated on the basis of prepubertal plasma levels multiplied with MCRs obtained in adults. Thus, multiplying for example the serum concentration of estradiol in prepubertal boys given in (14) with the MCR for estradiol in adult women given in (9) gives exactly the PR value for estradiol in prepubertal boys, $6.5 \mu \mathrm{g} /$ day, which is stated in the JECFA report (Table 1).

It is highly questionable whether MCRs for sex steroids defined in adults can be used to calculate PRs in children. MCR of sex steroids are influenced by several factors (for reviews see 16,17). The MCR is related to body size and should be expressed as a function of surface area to facilitate comparison (7). Using a MCR estimated in adults to calculate a PR in children without correcting for the difference in body size may introduce an approximately 2- to 3-fold overestimation of the PR as the body surface area of a 3- to 4-year-old child is approximately $30-50 \%$ of an adult woman. Two other factors which are known to influence the MCR of sex steroids are the binding capacity of serum transport protein and the enzymatic activity in the metabolizing tissues (mainly liver). Both these factors are partly affected by the endogenous hormonal status, including the levels of the sex steroids themselves as well as other hormones such as thyroid hormones. The bulk of both testosterone and estradiol in plasma are bound with high affinity to sex hormone-binding globulin (SHBG, previously also called testosterone-binding globulin or TeBG). Since, in general, only the free fraction of steroid is available for metabolic clearing, the MCR is inversely related to the fraction of the hormone bound to SHBG (18) (for review see also 16). In other words, the higher 
Table 1 Examples of estimates of daily production rates (PR) of estradiol based on various published data on estradiol serum concentrations in prepubertal boys and a metabolic clearance rate (MCR) estimated in women.

\begin{tabular}{|c|c|c|c|c|c|c|}
\hline \multirow[b]{3}{*}{ Source } & \multicolumn{4}{|c|}{ Serum estradiol } & \multirow{3}{*}{$\begin{array}{l}\text { MCR }^{\text {a }} \\
\text { (I/day) }\end{array}$} & \multirow{3}{*}{$\begin{array}{c}\mathbf{P R}^{\mathbf{b}} \\
(\mu \mathrm{g} / \text { day })\end{array}$} \\
\hline & \multirow[b]{2}{*}{ Assay } & \multicolumn{2}{|c|}{ Boys in pubertal stage I } & \multirow{2}{*}{$\begin{array}{c}\mathrm{pg} / \mathrm{ml} \\
\text { (mean } \pm \text { S.D.) }\end{array}$} & & \\
\hline & & Age in years (mean \pm S.D.) & $n$ & & & \\
\hline $\begin{array}{l}\text { Bidlingmaier et al. } \\
\text { (40) }\end{array}$ & RIA & $7.1^{\mathrm{c}}$ & 27 & $7.5 \pm 2.8$ & $\begin{array}{r}1350^{\mathrm{d}} \\
540^{\mathrm{e}}\end{array}$ & $\begin{array}{r}10.1 \\
4.1\end{array}$ \\
\hline $\begin{array}{l}\text { Angsusingha et al. } \\
\text { (14) }\end{array}$ & RIA & $11.2 \pm 0.4$ & 6 & $4.8 \pm 1.5$ & $\begin{array}{r}1350^{\mathrm{d}} \\
540^{\mathrm{e}}\end{array}$ & $\begin{array}{l}6.5^{f} \\
2.6\end{array}$ \\
\hline $\begin{array}{l}\text { Ducharme et al. } \\
\text { (41) }\end{array}$ & $\mathrm{RIA}$ & $6-8^{9}$ & 9 & $23^{c}$ & $\begin{array}{r}1350^{d} \\
540^{e}\end{array}$ & $\begin{array}{l}31 \\
12.4\end{array}$ \\
\hline $\begin{array}{l}\text { Baker et al. } \\
(42)\end{array}$ & RIA & $8.5 \pm 3.4$ & 9 & $5.3 \pm 3.2$ & $\begin{array}{r}1350^{\mathrm{d}} \\
540^{\mathrm{e}}\end{array}$ & $\begin{array}{l}7.2 \\
2.9\end{array}$ \\
\hline $\begin{array}{l}\text { Klein et al. } \\
\text { (23) }\end{array}$ & RCBA & $9.5 \pm 2.1$ & 23 & $0.08 \pm 0.2$ & $\begin{array}{r}1350^{\mathrm{d}} \\
540^{\mathrm{e}}\end{array}$ & $\begin{array}{l}0.1 \\
0.04\end{array}$ \\
\hline
\end{tabular}

${ }^{a} \mathrm{MCR}$ in adult women, from Longcope et al. (9). ${ }^{\mathrm{b}} \mathrm{PR}$ calculated as serum concentration $(\mathrm{pg} / \mathrm{ml}) \times \mathrm{MCR}(\mathrm{ml} / \mathrm{day}) .{ }^{\mathrm{c}}$ Only the mean is given in the paper. ${ }^{d} \mathrm{MCR}$ in adult women not corrected for the difference between body surface area in adult women and children. ${ }^{e} \mathrm{MCR}$ in adult women corrected by a factor of 0.4 for an approximate difference between body surface area in adult women and children. ${ }^{\mathrm{f}}$ The production rate for estradiol in prepubertal boys given in the JECFA report (4). ${ }^{9}$ Only the range is given.

$\mathrm{RIA}$, radioimmunoassay; RCBA, recombinant cellular bioassay.

the levels of SHBG, the higher the binding capacity in plasma and the lower the MCR. After steroids are extracted from plasma by the liver, they are metabolized in the microsomes. The effectiveness by which they are metabolized is determined by the activity of the enzymes involved, including reductase activity. Both thyroid hormone and androgens have been shown to increase reductase activity. The MCR of sex steroids is generally significantly higher in adult men compared with women; presumably due both to the lower plasma levels of SHBG and the higher reductase activity in the hepatic microsomes in men. Prepubertal children have substantially higher SHBG plasma levels than adults (Table 2), and therefore can be expected to have significantly lower MCRs for sex steroids than adults, even when MCRs are corrected for differences in body size. Less is known about the activity of the microsomal enzymes involved in steroid metabolism in children as compared with adults. However, there are no data suggesting that the enzyme activity should be higher in prepubertal children than in adults.

All these data strongly indicate that the MCRs of sex steroids in healthy prepubertal children can be expected to be substantially lower than in adults. A qualified guess would be that, for example, the MCR of estradiol in prepubertal children is at least 2 to 4 times lower than the MCR estimated in adult women (due to correction for differences in body size and SHBG levels).

The other factor in the calculation of the daily production rate of a given hormone is the plasma concentration of the hormone in question. The plasma levels of testosterone and estradiol in prepubertal children are most often below or close to the detection limit of the assays that have been used during the past decades. Problems in measuring low levels of steroids precisely have been recognized by studies showing high variation in the concentrations obtained between different assay methods and different laboratories (19-21). Thus, levels of sex steroids measured in prepubertal children can be regarded as relatively uncertain estimates. It should also be noted that serum levels of both testosterone and estradiol seem to increase slightly with age, even before the onset of puberty. Thus, in a cross-sectional study of more than 200 prepubertal children (all in Tanner stage I), we found that with increasing age an increasing fraction of the children had levels of estradiol and testosterone above the detection limits of the respective assays (Table 3) (22 and A-M Andersson unpublished data). The lowest serum sex steroid levels can therefore

Table 2 Mean SHBG concentrations in healthy prepubertal children and adults.

\begin{tabular}{|c|c|c|c|c|}
\hline & $\begin{array}{c}\text { Prepubertal boys } \\
\text { (Tanner } 1,6-13 \text { years) }\end{array}$ & $\begin{array}{c}\text { Prepubertal girls } \\
\text { (Tanner } 1,6-12 \text { years) }\end{array}$ & $\begin{array}{l}\text { Adult men } \\
(18-40 \text { years })\end{array}$ & $\begin{array}{l}\text { Adult women } \\
\text { (18-40 years) }\end{array}$ \\
\hline Mean (s.D.) (nmol/l) & $116(36.0)$ & $113(38.4)$ & $35(15.0)$ & $80(47.9)$ \\
\hline Number & 139 & 105 & 589 & 452 \\
\hline
\end{tabular}

SHBG concentrations measured in hormone laboratory at Dept. of Growth and Reproduction, Copenhagen University Hospital. 
Table 3 Fraction (and percent) of prepubertal children with estradiol and testosterone levels above the detection limits in the respective radioimmunoassays at $6-8$ and $10-13$ years of age.

\begin{tabular}{|c|c|c|c|c|}
\hline & \multicolumn{2}{|c|}{ Prepubertal boys } & \multicolumn{2}{|c|}{ Prepubertal girls } \\
\hline & $6-8$ years & $10-13$ years & $6-8$ years & $10-12$ years \\
\hline Testosterone & $1 / 31(3 \%)$ & $34 / 56$ (61\%) & $6 / 35(17 \%)$ & $20 / 33$ (61\%) \\
\hline Estradiol & 4/26 (15\%) & $24 / 55$ (44\%) & $14 / 35(40 \%)$ & 23/32 (72\%) \\
\hline
\end{tabular}

Testosterone and estradiol levels were measured by direct immunoassays at the Dept. of Growth and Reproduction, Copenhagen University Hospital.

Detection limits: testosterone assay $=66 \mathrm{pg} / \mathrm{ml}$; estradiol assay $=5 \mathrm{pg} / \mathrm{ml}$.

presumably be found in the younger (1- to 6-year-old) non-pubertal children.

Recently, Klein and coworkers (23) developed an ultrasensitive and highly specific assay for measuring estradiol in prepubertal children. Results obtained with this new assay indicated that levels of estradiol in prepubertal boys may be more than 100 times lower than previously published (23). Although the low levels obtained by Klein and coworkers need to be confirmed by other methods, they strongly point to the fact that a substantial uncertainty exists regarding the true serum levels of estradiol in prepubertal children. Thus, not only the MCRs, but most likely also the plasma concentrations used to calculate the PRs of estradiol in prepubertal children stated in the Thirty-second report on the joint $\mathrm{FAO} / \mathrm{WHO}$ expert committee on food additives: Evaluation of certain veterinary drug residues in food may be highly overestimated. Table 1 illustrates the high variation in estimates of $\mathrm{PR}$ for estradiol in prepubertal boys due to differences in measured serum concentrations and correction for MCR. The estimated PR for estradiol in prepubertal boys used by JECFA and subsequently by the FDA may be up to 100 to 200 times higher than the actual PR $(6.5 \mu \mathrm{g} /$ day vs $0.04 \mu \mathrm{g} /$ day $)$ (Table 1). It must, however, be kept in mind that large uncertainty regarding both MCR and serum levels of estradiol in young non-pubertal children still exists. Reconsidering the FDA guidelines for acceptable excess exposure to sex steroids through food (5), using a reevaluated PR for estradiol corresponding to approximately $0.04 \mu \mathrm{g} /$ day in boys (see Table 1), a $1 \%$ increase would correspond to $0.4 \mathrm{ng}$ estradiol per day. The question is whether exposure from eating meat from hormone-treated cattle can be expected to meet or exceed this level. Based on the review by JECFA in 1988 (4), estradiol levels in muscle tissue of treated calves, heifers and steers were in the range of $5-100 \mathrm{ng} / \mathrm{kg}$ above the levels found in untreated animals. In addition, a varying degree of increased levels of estrone (an estrogenic estradiol metabolite) were also observed. Other estrogenic metabolites may also be present in elevated levels in tissues from treated animals, although these were not reported. With a daily intake of $100 \mathrm{~g}$ meat this would correspond to an exogenous supply of $0.5-10 \mathrm{ng} /$ day estradiol plus a varying amount of metabolites with varying estrogenic activity. How much actually enters the body depends on the oral bioactivity of the given steroid, which for estradiol and estrone is relatively low. Other metabolites, e.g. estrone sulfate, have a high oral bioactivity and, once inside the body, can be converted to estrone and estradiol.

It should also be remembered that the given levels of residues in animal tissues are measured by the same types of methods that are suspected to overestimate low levels of steroid. Therefore, residue levels in animal tissue may be overestimated in line with the discussion on prepubertal sex steroid levels. However, even with these reservations, it cannot be excluded that the increase in exogenous supply of estrogens from the consumption of meat from treated animals may exceed $1 \%$ of the daily production rate in non-pubertal boys.

\section{Biological effects of low doses of sex steroids}

Although the role of sex steroids for growth, maturation and reproductive function has long been recognized, most effects have been attributed to pubertal or adult levels of steroid. Much less is known about the biological role of prepubertal levels of testosterone and progesterone. The possibility that very low doses of especially estradiol may also have a significant biological effect has only recently started to emerge. Therefore, in the following pages, we will concentrate on presenting the current knowledge of the effects of estrogens.

Most of our knowledge of the effect of low dose estrogen on epiphyseal growth comes from clinical studies in girls with Turner syndrome, in which it has been suggested that estrogen has a biphasic doseresponse relationship for epiphyseal growth, with stimulation at low levels and a reduced effect, or even inhibition, at high levels (24-26). In Turner girls, a dose of $100 \mathrm{ng} / \mathrm{kg} /$ day ethinylestradiol administered orally for 5 weeks resulted in a significantly increased growth velocity, whereas higher doses did not increase the growth rate. Although this low dose had a significant effect on growth, no effects on vaginal maturation or breast tissue were observed. In boys, short term treatment with a similar dose of infused estradiol has been shown to increase growth velocity 
(27). The above mentioned dose of $100 \mathrm{ng} / \mathrm{kg} / \mathrm{day}$ estrogen (corresponding to $4 \mu \mathrm{g} /$ day in a $40 \mathrm{~kg}$ child) is above our revised PR in prepubertal children and certainly above the estimated increased levels that can be expected from consumption of meat from animals treated according to good animal husbandry practice, especially as ethinylestradiol has a higher oral bioavailability than estradiol- $17 \beta$ (the oral bioactivity of ethinylestradiol and estradiol-17 $\beta$ is approximately $60 \%$ and $10 \%$ respectively). However, even lower levels of estrogen $(25-50 \mathrm{ng} / \mathrm{kg} /$ day ethinylestradiol) have been suggested for growth promotion in Turner girls (28). Furthermore, the growth stimulating effect of these doses was observed after a short period of treatment ( $3-5$ weeks).

Little is known about the dose-response relationship in the low dose-long term treatment/exposure situation. We can, however, get some clues from the gender differences in estradiol levels in normal prepubertal children. As previously mentioned, Klein and co-workers, using their ultra sensitive estradiol bioassay, recently were able to show that the levels of estradiol in prepubertal children of both sexes were substantially lower than those that had been determined previously by radioimmunoassay (23). In addition, they showed that the mean serum estradiol level $(0.6 \pm 0.6 \mathrm{pg} / \mathrm{ml})$ in prepubertal girls (5.5-10.5 years) was significantly greater than the level $(0.08 \pm 0.2 \mathrm{pg} / \mathrm{ml})$ in prepubertal boys (4.5-13 years). Although this difference is extremely small in absolute figures, prepubertal girls nevertheless have approximately eightfold higher estradiol levels than prepubertal boys.

This gender difference in serum estradiol levels may have biological implications and explain why girls mature faster than boys (23). Due to the biphasic action of estrogen on bone growth and maturation, higher levels of estrogen cause maturation and finally fusion of the epiphyses, which terminates linear growth (28). Thus, the higher childhood levels of estradiol in girls may explain their earlier puberty and their more rapid epiphyseal maturation. Even small changes of estradiol serum levels within the very low prepubertal range may, therefore, have significant biological implications.

Studies on low dose estrogen treatment have additionally shown that different target tissues have different sensitivity for estrogen. Thus, the studies in Turner girls showed that growth is extremely sensitive to the stimulatory effect of estrogen, whereas other effects such as vaginal maturation, breast development, onset of menses, and changes in SHBG levels were observed at higher doses of estrogen. In healthy postmenopausal women, signs of estrogenic stimulation have likewise been observed in some responsive tissues and not in others (19). These studies have shown that while the mean plasma estradiol concentration in these women was about $8 \mathrm{pg} / \mathrm{ml}$ (corresponding to $8 \mathrm{pg} / \mathrm{g}$ plasma), the concentrations found in vagina, endometrium and myometrium were 198, 655, and $149 \mathrm{pg} / \mathrm{g}$ respectively, demonstrating a very efficient accumulation of estradiol in these tissues (29). Breast tumor tissue has also been shown to have an increased concentration of estradiol compared with serum levels (30). Circulating estradiol is presumably not the only source of estradiol in these tissues. As previously mentioned, estrone sulfate, estrone, and estradiol are readily interconvertible. Data on estrogen metabolism in endometrial, vaginal, and mammary tumor tissue indicate that these tissues are very efficient at producing estradiol from precursor estrogens (estrone sulfate and estrone) (for reviews see 19, 31). Thus, circulating estrone sulfate and estrone may be at least as important as estradiol for the final concentration of estradiol in some target tissues. Consequently, evaluation of exposure to these metabolites may be just as relevant as exposure to estradiol itself.

Steroid hormones are implicated in a range of cancers, including breast and cervical cancers in women, prostate and testicular neoplasia in men, and other diseases such as polycystic ovary syndrome and malformations of the external and internal genitalia.

Carcinogenic and teratogenic effects of estrogen have been demonstrated in animal exposure studies and implicated by data from women who were prenatally exposed to diethylstilbestrol (DES). However, the doses of estrogen involved in these animal experiments and the doses of DES that were given to pregnant women were very high and clearly supra-physiological, and the question is whether very low levels of estrogen are totally irrelevant in this respect. In other words - is there a threshold dose for the observed effects of estrogen? As mentioned, the findings in Turner girls demonstrated that tissues have different sensitivities towards estrogen, indicating that specific threshold doses may apply for different tissues. Breast development, cornification of vaginal epithelium and similar indications of estrogen action are all morphological changes. Although biochemical changes (e.g. changes in gene expression, in signal transduction and in cell cycle regulation) may be much more subtle than morphological changes, they are certainly equal if not more important consequences of estrogen action. After all, the morphological changes observed following estrogen action are the result of preceding biochemical changes.

As biochemical changes are more complex to study, our knowledge of the dose-response relationship of estrogens for biochemical changes is more limited. Colleagues from our department have demonstrated specific gene activation by estrogen in the MCF7 breast cancer cell line in experimental in vitro studies using estrogen concentrations as low as $10^{-14} \mathrm{~mol} / \mathrm{l}$ in the cell medium ( $\mathrm{H}$ Leffers, unpublished observations). In reality, this concentration corresponds to $10-100$ molecules per cell in the culture well, indicating that as little as a few molecules of estrogen are able to exert a 
significant and measurable change in a cell's gene expression. Similarly, Masamura and coworkers (32) have shown that estradiol concentrations as low as $10^{-14}$ $10^{-15} \mathrm{~mol} / \mathrm{l}$ are sufficient to maximally stimulate replication of MCF7 cells with enhanced sensitivity to estradiol due to previous estradiol deprivation. Sheehan and coworkers (33) have recently pointed to the fact that the concept of a threshold level (which is the basis for determining a no observed effect level (NOEL)), may not always hold for exogenous administration of a hormone that has the same action as an endogenously produced hormone. Using estradiol-induced sex reversal of turtle embryos, they showed that if the threshold for estrogen action is already exceeded by endogenous estrogen, no threshold dose exists for the action of exogenous estrogens (33).

What signs then would we expect to observe in a population exposed to excessive but low levels of estrogen based on the above discussion? We may suspect a slightly younger age of pubertal onset and therefore a slight decrease in the age when final height is achieved. In addition, an increase in estrogen-related diseases and cancer forms (mainly breast cancer) would be expected. More subtle biochemical effects may not be recognized except if they lead to explicit adverse effects and even if or when they do, the original cause (i.e. hormonal action) may not be recognized.

The incidence of breast cancer is increasing in Western countries and has been doing so for several decades. The etiology of cancer is largely unknown and is presumed to involve both genetic preposition and environmental factors. There has also been a decrease in the age of onset of pubertal development in Western countries during this century. At present, this trend is generally attributed to the improved nutritional status. Although isolated signs of estrogenic stimulation (e.g. breast and/or pubic hair development) are not that uncommon in very young girls in the USA (seen at 7 years of age in $27.2 \%$ of African-American and $6.7 \%$ of white American girls (34)), earlier reliable data are missing in order to determine whether the incidences are increasing. Thus, although great concern regarding the role of environmental compounds with estrogenic activity on the development of hormone-related diseases and wildlife and human fertility has been raised, a clear connection may be extremely difficult to prove based on population data. The relatively few examples of a connection between environmental compounds with estrogenic activity and proven adverse effects on human or wildlife health are based on accidental exposures involving relatively large exposure doses.

A phenomenon which is important to mention in this connection, is the theory of hormonal imprinting. The term 'hormonal imprinting' covers experimental observations, which suggest that influences acting on hormone receptors during a critical period of maturation play a decisive role in the development and responsiveness later in life (35). Thus, a single perinatal treatment with the synthetic estrogens DES and allylestrenol has been shown to give rise to a lasting decrease in the number of rat uterine estrogen receptors (36) and to a lasting change in the responsiveness to testosterone by the microsomal enzyme activity of rat liver (37). Likewise, a single injection of testosterone in female neonatal rats has been shown to introduce lasting changes in estrogen responsiveness (38). It must, therefore, be recognized that a single supraphysiological dose of steroid hormone (or hormone analogs) at a critical time of development may have profound and lasting effects on the developing organs and their future responsiveness to hormone. It may be speculated that even hormonal changes within the physiological range may influence the fine-tuning of hormone sensitivity which may play a role later in life.

\section{Differences between the action of natural and synthetic steroid hormones}

It is important to bear in mind that the considerations discussed in the present paper only apply to natural steroid hormones. The action of the synthetic hormones used in cattle may diverge from endogenous steroids in a number of ways, some of which should be mentioned.

1. Many synthetic sex steroids have a low affinity for SHBG (39) and are present in an unbound form and biologically active in plasma. In contrast, approximately 98-99\% of the endogenous sex steroids are bound to SHBG in plasma. Therefore, even though the actual plasma concentrations of the synthetic sex hormones may be similar or even lower than the endogenous steroids, their biological action may be much stronger. 2. Synthetic sex hormones may be metabolized differently and have different half lives to endogenous steroids.

3. Although synthetic sex hormones may have certain effects in common with the endogenous hormones, their action may not be identical in all respects.

The synthetic sex hormones zeranol, melengestrol acetate and trenbolone acetate and their metabolites do not occur naturally in animals and humans. They have, to our knowledge, no legitimate use in humans and consequently all our information of their in vivo activity is limited to studies in animals. Different effects and consequences of exposure to these hormones may be expected and should be considered.

\section{Conclusion}

We have made a critical re-evaluation of available data on which current recommendations for the administration of certain sex steroids in agricultural practice are based. The data we had access to mainly derived from the thirty-second report of the joint FAO/WHO expert committee on food additives from 1988 and from monographs from the same meeting $(4,6)$. In this 
present paper, the data from 1988 by the FAO/WHO expert committee are re-evaluated in the light of new information coming from recent progress in hormone research.

Several points may flaw the validity of the conclusions of the $\mathrm{FAO} / \mathrm{WHO}$ expert committee.

1. The data on residue levels in animal tissue presented were based on studies performed in the $1970 \mathrm{~s}$ and $1980 \mathrm{~s}$ using the RIA methods available at the time. The sensitivity of the methods was generally inadequate to measure precisely the low levels found in animal tissues, and considerable variation between different RIA methods for measuring steroids exists. Therefore, the reported residue levels may be subject to considerable uncertainty.

2. Only limited information on the levels of the various steroid metabolites was reported despite the fact that this information is very relevant as some of these metabolites also have biological activity.

3. Reliable data on daily production rates of steroid hormones were and are still lacking in healthy prepubertal children. This lack is crucial as previous conclusions and guidelines regarding the acceptable levels of steroid residues in edible animal tissues have been based on very questionable estimates of production rates in children. Thus, even today the US FDA bases its guidelines on acceptable residue levels in tissue from hormone-treated animals on the presumably highly overestimated production rates in prepubertal children given in the JECFA report.

4. The possible biological significance of very low levels of estradiol, especially in children, is largely neglected.

In summary, steroid hormones are very potent compounds that have profound biological effects in both animals and humans. Most of our previous knowledge of the biological action of these compounds is based on the effects of adult physiological or supraphysiological doses of hormone. Recent in vivo studies in prepubertal children indicate that even small differences in hormone levels and very low doses of steroid hormone may have significant biological effects. Likewise, recent in vitro research has shown significant molecular effects of estrogen in extremely low doses. Special concern should be addressed to the lasting effects that may occur during specific sensitive time points of development, mainly during the fetal, perinatal and pubertal periods. Thus, it seems more and more evident that in practice no threshold level exists regarding the action of exogenous estrogen (and perhaps other steroid hormones as well), thus emphasizing the potent role of steroid hormones in regulating developmental events and basic functions by acting at the molecular level.

In the light of recent progress in our understanding of estrogen levels in children, we conclude that possible adverse effects on human health by consumption of meat from estrogen-treated animals cannot be excluded.

\section{Acknowledgements}

The work was supported by grants from the European Union and the Danish Medical Research Council.

\section{References}

1 European Workshop on the Impact of Endocrine Disrupters on Human Health and Wildlife (Weybridge Report). EUR 17549 $19961-125$.

2 Kavlock RJ, Daston GP, DeRosa C, Fenner-Crisp P, Gray LE, Kaattari S et al. Research needs for the risk assessment of health and environmental effects of endocrine disruptors: a report of the US EPA-sponsored workshop. Environmental Health Perspectives $1996104715-740$.

3 Toppari J, Larsen JC, Christiansen P, Giwercman A, Grandjean P, Guillette Jr LJ et al. Male reproductive health and environmental xenoestrogens. Environmental Health Perspectives 1996104 741803.

4 The joint FAO/WHO Expert Committee on Food Additives. Residues of some veterinary drugs in animals and foods. Food and Agriculture Organization of the United Nations 1988 FAO Food and Nutrition paper 41 .

5 US Food and Drug Administration. Guideline 3, part 2: Guideline for toxicological testing. www.fda.gov 1999 1-5.

6 The joint FAO/WHO Expert Committee on Food Additives. Evaluation of certain veterinary drug residues in food. World Health Organization 1988 WHO Technical Report Series 763.

7 Bardin CW \& Lipsett MB. Testosterone and androstenedione blood production rates in normal women and women with idiopathic hirsutism or polycystic ovaries. Journal of Clinical Investigation $196746891-902$.

8 Hembree WC, Bardin CW \& Lipsett MB. A study of estrogen metabolic clearance rates and transfer factors. Journal of Clinical Investigation 196948 1809-1819.

9 Longcope C, Layne DS \& Tait JF. Metabolic clearance rates and interconversions of estrone and $17 \beta$-estradiol in normal males and females. Journal of Clinical Investigation 196847 93-106.

10 Mahoudeau JA, Bardin CW \& Lipsett MB. The metabolic clearance rate and origin of plasma dihydrotestosterone in man and its conversion to the $5 \alpha$-androstanediols. Journal of Clinical Investigation $1971501338-1344$.

11 Saez JM, Forest MG, Morera AM \& Bertrand J. Metabolic clearance rate and blood production rate of testosterone and dihydrotestosterone in normal subjects, during pregnancy, and in hyperthyroidism. Journal of Clinical Investigation 197251 1226-1234.

12 Ruder HJ, Loriaux L \& Lipsett MB. Estrone sulfate: production rate and metabolism in man. Journal of Clinical Investigation 197251 1020-1033.

13 Horton R \& Fraiser SD. Androstenedione and its conversion to plasma testosterone in congenital adrenal hyperplasia. Journal of Clinical Investigation 196746 1003-1009.

14 Angsusingha K, Kenny FM, Nankin HR \& Taylor FH. Unconjugated estrone, estradiol and $\mathrm{FSH}$ and $\mathrm{LH}$ in prepubertal and pubertal males and females. Journal of Clinical Endocrinology and Metabolism $19743963-68$.

15 Lippe BM, LaFranchi SH, Lavin N, Parlow A, Coyotupa J \& Kaplan SA. Serum 17- $\alpha$-hydroxyprogesterone, progesterone, estradiol, and testosterone in the diagnosis and management of congenital adrenal hyperplasia. Journal of Pediatrics $197485782-787$.

16 Lipsett MB. Factors influencing the rate of metabolism of steroid hormones in man. Annals of the New York Academy of Sciences $1971179442-449$.

17 Lipsett MB. Production of testosterone by prostate and other peripheral tissues in man. Vitamines and Hormones 197533 209221.

18 Vermeulen A, Verdonck L, Van der Straeten M \& Orie N. Capacity of 
the testosterone-binding globulin in human plasma and influence of specific binding of testosterone on its metabolic clearance rate. Journal of Clinical Endocrinology 196929 1470-1480.

19 Carlstrom K. Low endogenous estrogen levels - analytical problems and tissue sensitivity. Acta Obstetrical and Gynecological Scandinavica $19967511-15$.

20 Potischman N, Falk RT, Laiming VA, Siiteri PK \& Hoover RN. Reproducibility of laboratory assays for steroid hormones and sex hormone-binding globulin. Cancer Research $1994545363-$ 5367.

21 Wheeler MJ, D’Souza A, Matadeen J \& Croos P. Ciba Corning ACS:180 testosterone assay evaluated. Clinical Chemistry 1996 42 1445-1449.

22 Andersson A-M, Juul A, Petersen JH, Müller J, Groome NP \& Skakkebæk NE. Serum inhibin B in healthy pubertal and adolescent boys: relation to age, stage of puberty, and folliclestimulating hormone, luteinizing hormone, testosterone and estradiol levels. Journal of Clinical Endocrinology and Metabolism 199782 3976-3982.

23 Klein KO, Baron J, Colli MJ, McDonnell DP \& Cutler GB Jr. Estrogen levels in childhood determined by an ultrasensitive recombinant cell bioassay. Journal of Clinical Investigation 199494 2475-2480.

24 Ross JL, Cassorla FG, Skerda MC, Valk IM, Loriaux DL \& Cutler GB. A preliminary study of the effect of estrogen dose on growth in Turner's syndrome. New England Journal of Medicine 1983309 1104-1106.

25 Ross JL, Long LM, Skerda MC, Cassorla FG, Kurtz D, Loriaux DL et al. Effect of low doses of estradiol on 6-month growth rates and predicted height in patients with Turner syndrome. Journal of Pediatrics 1986109 950-953.

26 Mauras N, Rogol AD \& Veldhuis JD. Specific, time-dependent actions of low-dose ethinyl estradiol administration on the episodic release of growth hormone, follicle-stimulating hormone, and luteinizing hormone in prepubertal girls with Turner's syndrome. Journal of Clinical Endocrinology and Metabolism 1989 69 1053-1058.

27 Caruso-Nicoletti M, Cassorla FG, Skerda MC, Ross JL, Loriaux DL \& Cutler GB. Short term, low dose estradiol accelerates ulnar growth in boys. Journal of Clinical Endocrinology and Metabolism $198561896-898$.

28 Cutler GB. The role of estrogen in bone growth and maturation during childhood and adolescence. Journal of Steroid Biochemistry and Molecular Biology 199761 141-144.

29 van Haaften M, Donker GH, Haspels AA \& Thijssen JH. Oestrogen concentrations in plasma, endometrium, myometrium and vagina of postmenopausal women, and effects of vaginal oestriol (E3) and oestradiol (E2) applications. Journal of Steroid Biochemistry $198933647-653$.

30 Masamura S, Santner SJ, Gimotty P, Geroge J \& Santen RJ. Mechanism for maintenance of high breast tumor estradiol concentrations in the absence of ovarian function: role of very high affinity tissue uptake. Breast Cancer Research and Treatment $199742215-226$.

31 Masamura S, Santner SJ \& Santen RJ. Evidence of in situ estrogen synthesis in nitrosomethylurea-induced rat mammary tumors via the enzyme estrone sulfatase. Journal of Steroid Biochemistry and Molecular Biology 199658 425-429.

32 Masamura S, Santner SJ, Heitjan DF \& Santen RJ. Estrogen deprivation causes estradiol hypersensitivity in human breast cancer cells. Journal of Clinical Endocrinology and Metabolism 1995 $802918-2925$.

33 Sheehan DM, Willingham E, Gaylor D, Bergeron JM \& Crews D. No threshold dose for estradiol-induced sex reversal of turtle embryos: how little is too much? Environmental Health Perspectives 1999107 155-159.

34 Herman-Giddens ME, Slora EJ, Wasserman RC, Bourdony CJ, Bhapkar MV, Koch GG et al. Secondary sexual characteristics and menses in young girls seen in office practice: a study from the pediatric research in office settings network. Pediatrics 199799 505-512.

35 Csaba G. Phylogeny and ontogeny of hormone receptors: the selection theory of receptor formation and hormonal imprinting. Biology Reviews 198055 47-63.

36 Csaba G, Inczefi-Gonda A \& Dobozy O. Hormonal imprinting by steroids: a single neonatal treatment with diethylstilbestrol or allylestrenol gives rise to a lasting decrease in the number of rat uterine receptors. Acta Physiologica Hungarica 198667 207-212.

37 Csaba G, Szeberényi SZ \& Dobozy O. Influence of single neonatal treatment with allylestrenol or diethylstilbestrol on microsomal enzyme activity of rat liver in adulthood. Medicine and Biology 198664 197-200.

38 Mena MA, Arriaza CA \& Tchernitchin AN. Early postnatal androgenization imprints selective changes in the action of estrogens in the rat uterus. Biology of Reproduction 199246 1080-1085.

39 Sheehan DM \& Young M. Diethylstilbestrol and estradiol binding to serum albumin and pregnancy plasma of rat and human. Endocrinology 1979104 1442-1446.

40 Bidlingmaier F, Wagner-Barnack M, Butenandt O \& Knorr D. Plasma estrogens in childhood and puberty under physiologic and pathologic conditions. Pediatric Research 19737 901-907.

41 Ducharme J-R, Forest MG, De Peretti E, Sempé M, Collu R \& Bertrand J. Plasma adrenal and gonadal sex steroids in human pubertal development. Journal of Clinical Endocrinology and Metabolism $197642468-476$.

42 Baker HWG, Burger HG, De Kretser DM, Hudson B, O'Connor S, Wang $\mathrm{C}$ et al. Changes in the pituitary-testicular system with age. Clinical Endocrinology 19765 349-372.

Received 24 February 1999

Accepted 23 April 1999 